\title{
CORRECTION
}

\section{Correction to: Identification and salt tolerance evaluation of endophyte fungi isolates from halophyte plants}

\author{
B. Jalili ${ }^{1} \cdot$ H. Bagheri ${ }^{1} \cdot$ S. Azadi ${ }^{1} \cdot$ J. Soltani ${ }^{2}$
}

Published online: 24 August 2021

(c) Islamic Azad University (IAU) 2021

\section{Correction to: International Journal of Environmental Science and Technology \\ https://doi.org/10.1007/s13762-020-02626-y}

There was a mistake in the name of affiliation. It is written Bu Ali-Sina university, but it must be Bu-Ali Sina University (the place of-).

The original article can be found online at https://doi.org/10.1007/ s13762-020-02626-y.

\section{H. Bagheri}

1 Department of Biotechnology, Bu-Ali Sina University, Hamedan, Iran

2 Plant Pathology Section, Plant Protection Department, Bu-Ali Sina University, Hamedan, Iran 